\title{
ENSINO DE BIOLOGIA EM TEMPOS DE PANDEMIA: CRIATIVIDADE, EFICIÊNCIA, ASPECTOS EMOCIONAIS E SIGNIFICADOS
}

\author{
BIOLOGY TEACHING IN PANDEMIC TIMES: CREATIVITY, EFFICIENCY, \\ EMOTIONAL ASPECTS AND MEANINGS
}

\author{
Mônica Dias Soares ${ }^{1}$ \\ Antônia Nádia Brito dos Santos ${ }^{2}$ \\ Francielly Rodrigues de Farias ${ }^{3}$ \\ Filipe Gutierre Carvalho de Lima ${ }^{4}$
}

RESUMO: A pandemia causada pelo vírus (SARS-COV-2) desencadeou um novo panorama educacional, mesmo diante de inúmeros fatores, como, por exemplo: financeiros e de infraestrutura, a questão emocional advinda do isolamento social tornou-se um desafio para professores $\mathrm{e}$ estudantes. Visto que, grande parte das pesquisas publicadas até hoje estão focadas apenas no aluno, ressaltar a visão dos professores da rede pública é essencial para a sociedade reconhecer a importância destes e a experiência vivida no ensino remoto. O objetivo do estudo foi mostrar, através dos discursos dos professores, de que forma o isolamento social interferiu/contribuiu no ensino de Biologia, compreendendo em que aspecto o período de pandemia corroborou na inovação das aulas, na interação do professor/aluno e no aprendizado significativo, por fim, a postura dos professores quanto a formação continuada, aspectos emocionais e eficiência. Para isto, foram entrevistados professores de Biologia da rede pública do nível médio da região Norte do Ceará. Os resultados demonstraram que o ambiente virtual passou a ser o espaço de aprendizagem possível para o processo de formação, houve uma dificuldade em separar as atividades domiciliar e profissional. Outro desafio vivenciado foi a necessidade de desenvolver competências e habilidades para as tecnologias educacionais, nem sempre trabalhadas durante a formação inicial. Momento oportuno de uma reflexão crítica sobre o sistema de educação e de como superar as falhas existentes.

Palavras-chave: Ensino remoto. Formação Continuada. Isolamento social. Professores. Tecnologia educacional.

ABSTRACT: The pandemic caused by the virus (SARS-COV-2) triggered a new educational landscape, even in the face of numerous factors, such as: financial and infrastructure, the emotional

\footnotetext{
1 Acadêmica de Ciências Biológicas da Universidade Estadual Vale do Acaraú - UVA. Email: msoaresdias219@gmail.com.

${ }^{2}$ Acadêmica de Ciências Biológicas da Universidade Estadual Vale do Acaraú - UVA. Email: nadiabs_@outlook.com.

3 Acadêmica de Ciências Biológicas da Universidade Estadual Vale do Acaraú - UVA. Email: r.francielly@live.com.

4 Mestre e Professor adjunto da Universidade Estadual Vale do Acaraú-UVA. Email: filipe_carvalho@uvanet.br.
} 
issue arising from social isolation has become a challenge for teachers and students. Since, most of the research published to date is focused only on the student, highlighting the view of public school teachers is essential for society to recognize the importance of these and the experience lived in remote education. The objective of the study was to show, through the speeches of the teachers, how social isolation interfered / contributed in the teaching of Biology, understanding in what aspect the pandemic period corroborated in the innovation of the classes, in the teacher / student interaction and in the learning finally, the attitude of teachers regarding continuing education, emotional aspects and efficiency was significant. For this, biology teachers from public schools in the medium level of the North of Ceara were interviewed. The results showed that the virtual environment became the possible learning space for the training process, there was a difficulty in separating home and professional activities. Another challenge experienced was the need to develop competencies and skills for educational technologies, which were not always worked on during initial training. Timely moment for a critical reflection on the education system and how to overcome the existing failures.

Keywords: Remote education. Continuing education. Social isolation. Teachers. Educational technology.

\section{INTRODUÇÃO}

Um vírus de proporções letais e silencioso foi capaz de modificar mundialmente a rotina das pessoas e se proliferar rapidamente nos organismos de muitos levando à morte. No final de março, as perspectivas para o ano de 2020 foram adiadas, a liberdade não existia, apenas o medo, angústia, incertezas e insegurança se propagaram em todos os contextos sociais. A Organização Mundial de Saúde (OMS) juntamente com os profissionais da área tenta buscar uma forma de diminuir a disseminação do vírus, conhecido como SARS-COV-2. Porém, pouco se sabe sobre ele, enquanto isso, a espera por tratamento eficaz para o controle da pandemia é esperada por todos.

Nesse contexto, a principal forma de prevenção seria conter a proliferação do vírus, com as medidas básicas de higiene: lavagem das mãos e aplicação de álcool em gel, o uso de máscara e isolamento social. Com o fechamento da maioria dos estabelecimentos comerciais, escolas e universidades, um novo cenário das relações sociais começa a se desenhar tendo como princípio fundamental o isolamento.

Inúmeros seguimentos sofrem com o processo de adaptação, principalmente a educação, mesmo diante de inúmeros fatores como, por exemplo, financeiros e de infraestrutura, a questão emocional advinda do isolamento social tornou-se um desafio para professores e estudantes. Os professores do ensino básico precisaram mostrar eficiência e usarem a criatividade no planejamento de suas aulas. $\mathrm{O}$ ambiente virtual passou a ser o espaço de aprendizagem possível para o processo de formação. 
Outro desafio vivenciado foi a necessidade de desenvolver competências e habilidades para as tecnologias educacionais, nem sempre trabalhadas durante a formação inicial, único meio de contato e de relacionamento professor-aluno.

No atual momento, foi possível visualizar ainda mais as fragilidades e desafios do sistema educacional historicamente discutidos. As aulas presencias foram suspensas, e o ensino remoto foi aderido, uma vez que, conforme o artigo 205 da Constituição Federal da República:

A educação, direito de todos e dever do Estado e da família, será promovida e incentivada com a colaboração da sociedade, visando ao pleno desenvolvimento da pessoa, seu preparo para o exercício da cidadania e sua qualificação para o trabalho. (BRASIL,1988)

Devido ao isolamento social os educadores tiveram que se reinventar para dar continuidade as aulas e não deixar os estudantes desamparados. A discussão contextualizada sobre os aspectos biológicos oriundos do período pandêmico revelam a importância dos alunos se apropriarem dos conhecimentos das ciências biológicas possibilitando a intervenção crítica e argumentativa dos estudantes. O papel dos professores de Biologia, foi essencial na divulgação de informação para comunidade escolar.

O ensino de Biologia é essencial para o desenvolvimento de uma sociedade e provimento da melhoria da qualidade de vida da população pelo fato de apresentar, no seu escopo, uma gama de conteúdos científicos que abordam temas de extrema necessidade. Os temas referentes às questões ambientais; biotecnológicas; disseminações de doenças infectocontagiosas e de fisiologia e saúde humanas são alguns que denotam a grande necessidade do entendimento dessa ciência. (GOMES, 2018, p.20)

Os professores nesse contexto, encontraram grandes dificuldades, "cerca de 88\% dos deles nunca ministraram aulas virtuais antes.” (BENEDITO; FILHO, 2020, p.65) A falta de preparação diante dos novos meios de tecnologias digitais da informação e comunicação, tornou-se mais evidente, principalmente para aqueles professores que estavam acostumados com os métodos tradicionais de ensino.

Inúmeros são os problemas e contrastes descritos na literatura educacional e observados no processo educativo formal na formação inicial de professores no Brasil, na qual os docentes eram formados em escolas normais, não havendo necessidade de formação acadêmica, "Já que a exigência do nível superior se consolidou na legislação nacional apenas na segunda metade dos anos I990." (SEGATTO; LOUZANO, 2019, p.184) Isso favoreceu a falta de reconhecimento e valorização da profissão.

Diferente de outros países desenvolvidos, no Brasil ainda havia um descaso na estrutura curricular e na formação docente, com o distanciamento da escola, as disciplinas do ensino superior 
focavam apenas na teoria. Contudo, um licenciando sem prática pedagógica e convívio com os alunos, não estaria preparado para lecionar. Louzano et al (2019, p. 153), afirma que "a forma como o estudante é avaliado para definir sua capacidade de se tornar um bom professor está centrada na ideia de que ele deve demonstrar sua capacidade prática de ser professor, e não apenas a teórica.”

Com o surgimento de programas de formação docente como Programa Institucional de Bolsas de Iniciação à Docência (PIBID) e Programa de Residência pedagógica (PRP), aliados aos estágios supervisionados, os quais exigem uma vivência maior dos licenciandos na escola, contribuem com a formação prática dos alunos.

Contudo, os programas não comportam a demanda de estudantes, com isso a matriz curricular dos cursos de licenciaturas, busca através de metodologias ativas o real protagonismo do aluno. Mesmo diante dos avanços apresentados, a maioria das universidades públicas não possuem infraestrutura e um corpo de profissionais capacitados para contribuir na formação inicial.

Pesquisas mais recentes sobre o currículo de formação de professores no país apontam para a persistência dessa desconexão entre o que se ensina na universidade (pública ou privada) e o que o professor precisa fazer na sala de aula. (BORN,2019, p.25)

Dentre os desafios que se destacam nas aulas não presenciais, tem-se o trabalho em casa. A maioria dos educadores são pais e não dispõem de espaços adequados para separar suas atividades domiciliares das escolares, podendo ocorrer desvios de concentração por causa da interferência das pessoas que moram na mesma residência. Além disso, quando conseguem preparar suas aulas, a maior parte dos alunos não têm acesso à internet ou os pais preferem deixar os filhos realizando trabalhos domésticos no horário da aula.” [...]É sabido que 20\% dos domićlios brasileiros não possuem acesso à internet, nos quais vivem 7 milhões de estudantes, 95\% matriculados em escolas públicas.” (COLEMARX, 2020, p.I6).

Nesse novo cenário, é possível perceber uma aproximação mesmo que virtual dos professores/pais/alunos em busca do desenvolvimento da aprendizagem dos jovens. Contudo, os docentes não apenas são cobrados pela escola, para estar atualizando as atividades, como também pelos pais, para ajudar estes a ensinarem seus filhos. A jornada de trabalho aumentou significativamente, pois o educador está susceptível ao contato dos pais ou alunos em qualquer horário.

Outro fator a ser considerado, as metodologias ativas no ensino de Biologia, pois são indispensáveis para instigar a participação dos alunos, no entanto, com aulas virtuais os docentes buscam amenizar a falta dessa prática através de slides mais dinâmicos, um discurso mais curto e 
questionamentos. Mas, nem sempre é possível, pois boa parte das atividades remotas são através de exercícios do livro ou questionários. Um dos pontos positivos das atividades remotas, é o aprendizado e interesse dos professores em buscar as novas tecnologias, que poderão contribuir posteriormente nas aulas presencias.

Esse novo paradigma de instruir os jovens trarão inovações no contexto educacional. Tornando mais visíveis modelos de aprendizagem que, antes da pandemia, eram inviáveis, possíveis de serem aceitos na contemporaneidade. Como, por exemplo, a educação domiciliar ou homeschooling que pode ser definida como:

Substituição integral da frequência à escola pela educação doméstica, onde a responsabilidade pela educação formal dos filhos é atribuída aos próprios pais ou responsáveis. A criança ou adolescente não frequenta uma instituição de ensino, seja ela pública ou particular. As aulas são lecionadas em casa pelos genitores ou por professores particulares contratados por estes. (SILVA, 2020)

Muitos discutem sobre essa forma de adquirir conhecimento, pois a grande parte da população brasileira depende de instituição pública. No entanto, com as aulas online os pais mesmo com dificuldades se organizaram e conseguiram contratar um reforço ou um educador mais próximo. Essa vivência reflete os tempos passados, em que não existiam escolas públicas, e a família era a principal responsável por educar os jovens. Nos Estados Unidos, a educação domiciliar já é uma prática comum, por ser regularizada. No Brasil, segundo os dados da Associação Nacional da Educação Domiciliar (ANED), "cerca de 5000 estudantes entre 4 e 17 anos aderiram à modalidade". Contudo, está no processo de aceitação e regulamentação, segundo o Ministério da Educação, lei n.o 240I/19 caso seja aprovada pelo poder Executivo competem aos responsáveis:

[...] renovar anualmente, através de plataforma virtual do Ministério da Educação, com a inclusão do plano pedagógico individual correspondente ao novo ano letivo. O estudante matriculado em educação domiciliar, será submetido, para fins de certificação da aprendizagem, a uma avaliação anual sob a gestão do Ministério da Educação. (BRASIL, 2019)

Nessa perspectiva, cada vez mais mudanças surgirão e exigirá profissionais capacitados para acompanhar a evolução no panorama educacional. Além disso, o investimento na formação continuada é crucial no mercado de trabalho, principalmente, no que se refere ao uso das Tecnologias Digitais da Informação e Comunicação (TDICs). Essa forma de comunicação muito utilizada pelos jovens, os quais nos últimos anos estão cada vez mais conectados em redes sociais e aplicativos digitais. 
No entanto, as tecnologias digitais não eram valorizadas pelas instituições de ensino, pois a maioria dos professores possuía uma visão restritiva, falta de conhecimento, interesse e dificuldades com as plataformas digitais. Com o avanço da pandemia a importância do uso das TDICs se intensificaram, através destas foi possível dar continuidade às aulas nos diferentes níveis de ensino. No que se refere ao ensino de Biologia, segundo Gomes (2018, p.20):

\begin{abstract}
Em meio à complexidade do processo de ensino e aprendizagem de Biologia no Ensino Médio, o uso das tecnologias digitais de informações e comunicações surge como alternativa para facilitar esse processo, na mediação dos diversos temas pelo professor, mas se faz necessário à compreensão dos aspectos pedagógicos entremeados para sua efetiva utilização em plena era digital.
\end{abstract}

Desse modo, um olhar voltado a formação continuada dos professores, deve ser considerado no contexto atual. Haja vista, que os docentes são responsáveis por construir meios de formação dos indivíduos. No entanto, cabe ao profissional mais ainda procurar manter-se atualizado. O conhecimento dos educadores, em especial, os que ensinam Biologia, deve estar alinhado e constantemente, pois as informações variam e se aprimoram a cada instante. Consistente com essas observações:

[...] a formação continuada dos professores não deve ser entendida como um processo cumulativo de informações, bem como de conhecimentos, mas deve buscar o desenvolvimento profissional e pessoal, com foco no processo de desenvolvimento das competências políticas, técnicas e humanas do professor tendo em vista a melhoria da prática profissional. (FERREIRA; NETA, 2012, p.965)

O ensino remoto deixou claro que os professores de todos os níveis educacionais das escolas públicas, precisam ter mais compromisso em ampliar o aprendizado nas tecnologias digitais, através da formação continuada. Portanto, com o isolamento social e as mudanças no paradigma educacional, os professores foram mais vistos pelos pais e comunidade escolar como agentes essenciais na formação dos estudantes.

Diante do exposto, é importante focar no posicionamento dos professores da educação básica da rede pública frente aos problemas do ensino remoto, pois grande parte das pesquisas publicadas até hoje estão voltados para os discentes.

Partindo dessa ideia, objetivou-se através do presente estudo analisar através dos discursos dos professores de Biologia, da rede pública, nível médio, dos municípios da região norte do Ceará, no intuito de mostrar de que forma o isolamento social interferiu/contribuiu no ensino de Biologia, compreendendo em que aspecto o período de pandemia corroborou na inovação das aulas, na 
interação do professor/aluno e no aprendizado significativo, por fim, analisar a postura dos professores quanto a formação continuada, aspectos emocionais e eficiência.

\section{Metodologia}

A natureza da pesquisa é básica e qualitativa, busca mostrar através dos discursos uma visão geral acerca do posicionamento dos professores de Biologia sobre alguns aspectos vividos durante a pandemia com detalhamento e a interpretação dos significados.

O uso da descrição qualitativa procura captar não só a aparência do fenômeno como também suas essências, procurando explicar sua origem, relações e mudanças, e tentando intuir as consequências. (OLIVEIRA,20II, p.24)

Trata-se de um trabalho com abordagem exploratória, selecionado as experiências de um corpo docente pequeno, direcionado ao acaso, especificando as principais descobertas para uma melhor compreensão. De acordo com Malhotra (20or), a pesquisa exploratória:

É usada em casos nos quais é necessário definir o problema com maior precisão. Tem as seguintes características: informações definidas ao acaso e o processo de pesquisa flexível e não-estruturado. A amostra é pequena e não-representativa e a análise dos dados é qualitativa.

O instrumento utilizado para coleta de dados foi através de uma entrevista, dividida em quatro secções: (I) ensino remoto de Biologia (2) metodologias e criatividade (3) formação continuada (4) eficiência e aspectos emocionais. A forma de divulgação e acesso aos participantes ocorreu virtualmente via aplicativo de WhatsApp e e-mail.

A estrutura dos questionamentos propostos baseia-se na perspectiva dos objetivos desta pesquisa, a saber: de que forma o ensino remoto interferiu/contribuiu em seu cotidiano como professor(a) de Biologia? Qual a principal metodologia de ensino? E a relação com os alunos e pais? Como foi se adequar às novas plataformas digitais/tecnologias em geral? A escola forneceu instrução ou formação continuada para uso delas? Quais os pontos positivos e negativos do ensino remoto? Com a junção das atividades pessoais e profissionais, como você avalia sua eficiência e aspecto emocional?

O estudo se direcionou a oito professores de Biologia, denominados: de PRs, da região Norte do Ceará, sendo duas (Massapê-CE), três (Sobral - CE), duas (Uruoca-CE) e uma em (TianguáCE). Todos vivenciaram o ensino remoto no nível médio, dentre estes cerca 80\% lecionavam em escolas estaduais profissionalizantes, e $20 \%$ escola estadual regular. 
A seleção das considerações apresentadas pelos professores seguiu uma linha de representatividade diante dos questionamentos apresentados. A omissão das demais respostas, deuse pelo fato de que estas já estavam contempladas em colocações anteriores.

Considerando os princípios éticos da pesquisa, para assegurar a confidencialidade das informações, foi enviado a cada professor o Termo de Consentimento Livre e Esclarecido (TCLE), destacando os objetivos da pesquisa, uma breve introdução com dados do pesquisador, instituição e orientador.

\section{Resultados e Discussões}

Diante do contexto educacional causado pela pandemia, conhecer as vivências dos professores de Biologia da rede pública, contribuirá para a discussão da temática em questão, mostrando as dificuldades e superações vivenciada pelo educador, devido ao ensino remoto.

Se entendíamos que ensinar é transferir saber, fomos levados a ver que ensinar é muito mais criar possibilidade para a sua produção. A relação ensino-aprendizagem é dialógica, feita entre sujeitos ativos.

(OLIVEIRA,2020, p.37)

A partir das reflexões dos professores de Biologia, participantes da pesquisa, tendo como base os questionamentos abordados durante a aplicação da entrevista, pôde-se observar quando questionados sobre as contribuições e interferências do ensino remoto, a saber:

PR or: " Dar aulas à distância foi um grande desafio, houve uma falta de estimulação dos alunos, pois presencialmente acompanho desenvolvimento deles, instigando e motivando-os."

PR o3: "O ensino remoto favoreceu um maior conhecimento das tecnologias digitais, mas foi possível reconhecer o quanto o professor é essencial na sala de aula."

PR 05: "Apesar de trabalharmos em casa, interferiu no aumento da carga horária. E ainda a modalidade de ensino remoto percebi que o mesmo é mais quantitativo do que qualitativo. Deixa lacuna."

PR o6: "O ensino remoto interferiu na quebra de privacidade, já que meu ambiente de trabalho agora é a minha casa, local onde antes era apenas de convivência familiar e outras atividades pessoais “

PR 07: "Tive que me adaptar às mudanças que foram impostas, pela pandemia, como manusear algumas plataformas digitais e aplicativos, até então desconhecidos ou pouco explorados. As aulas remotas irão contribuir nas aulas presenciais, pois ainda será utilizada de forma secundária (questionário e revisão de prova e o vídeo online será um novo meio de tirar dúvidas em horários extra-aula." 
É notória a sensação de um momento desafiador em relação às práticas educacionais frente ao cenário pandêmico, através da intensa e necessária adaptação e formação. Com base nessas reflexões, podemos usar das colocações de Oliveira (2020, p.38), ao destacar que:

Hoje, podemos nos dar por privilegiados diante de uma calamidade como a pandemia. Fomos desafiados a assumir a tecnologia como nossa grande parceira. Descobrimos que nossas aulas podem ser muito melhores, graças às ferramentas disponíveis nas diversas plataformas. A pandemia nos colocou a tecnologia como nossa aliada. Não estávamos preparados para tanto de uma só vez. Mas tivemos que romper as nossas barreiras, superar nossas resistências e até nossos preconceitos.

Dentre várias adaptações, o ensino convencional foi substituído por novas plataformas digitais. Exigindo habilidades e competências que até então, não era trabalhado com os licenciados. Além disso, o método de avaliar o aluno, tornou-se mais complexo, deixando em evidência que a prática de avaliação por meios únicos, como exemplo a prova, é um método ultrapassado.

No atual contexto da COVID-ı́ em que a convergência entre o virtual e o presencial não permite mais lançar mão da educação convencional e, consequentemente, dos princípios de uma avaliação também convencional, só nos resta configurar a subjetividade individual e social para a continuidade das ações. (PASCHOALINO; RAMALHO; QUEIROZ, 2020, p.127).

Sobre as metodologias de ensino e avaliação dos resultados obtidos, os professores relatam:

PR or:" A metodologia usada foi o Google meet (aula online), Zoom (gravação de aulas e "slides") Google sala de aula (atividades feitas pelos alunos), esse último foi a principal forma de verificar se alunos estão fazendo os exercícios, pois eles mandavam e, em contrapartida havia um retorno através de correções e explicações das questões propostas. Avaliar o aluno vai muito além de uma simples prova, pois nesse modelo de provas on-line, ele pode pesquisá-la a qualquer momento. Então analisa-se o compromisso e o respeito com o professor, como, por exemplo, em entregar todas as atividades realizadas em um período determinado."

PR 03: “Nas aulas remotas foram utilizadas principalmente slides, vídeos-aulas e atividades para aplicação dos conteúdos, que foram expostos no Classroom e Google Meet. Os alunos apresentaram mais dificuldades para compreender os conteúdos, apesar do ritmo ser bem menor do que nas aulas presenciais, pediam constantemente para repetir as explicações. O retorno dos alunos não foi satisfatório, poucos participavam e a frequência foi muito baixa em todas as aulas, podendo então ser avaliado um baixo rendimento nos conhecimentos das turmas. Sentiu-se a necessidade do olho no olho para observação do aluno diante da aplicação dos conteúdos para a avaliação oral. Além disso, a ausência de uma visão geral da turma também comprometeu processo de ensino, aprendizagem, visto que o professor não pode ter a certeza de que aluno está respeitando sua aula no momento. A turmas estavam divididas por ano e comprometeu a relação professor aluno, pois cada turma tem suas particularidades com o professor e professor com os alunos."

PR o5: "Para os alunos com acesso à internet minhas principais metodologias são a postagem de videoaulas (gravadas por mim ou já gravadas por outros professores no YouTube) seguidas de questões elaboradas a partir do conteúdo contido no livro didático ou que já tenham no próprio livro. Vale lembrar que as postagens são através do Google ClassRoom 
ou WhatsApp. Além disso, também temos os encontros online através do App Google Meet. Temos ainda os alunos sem acesso à internet que o atendimento se faz via material impresso, através de apostilas de apoio com mapas mentais, desenhos e esquemas que facilitem a aprendizagem. A avaliação é feita através de aplicação de formulários online e das devolutivas das atividades feitas pelo Google ClassRoom ou WhatsApp."

Constata-se por esses discursos que a necessária formação de professores a partir das Tecnologias Digitais de Informação e Comunicação, para que sejam desenvolvidas as competências necessárias ao processo de ensino e de aprendizagem, estejam presentes no ideário de formação inicial e continuada, de modo a atender as atuais demandas provenientes do isolamento social e de uma nova ordem de linguagens e comunicação vigente. Nesse aspecto, conforme Silva, (2018, p. 3435):

[..] nota-se que o uso e a inserção de tecnologias digitais nas práticas de ensino constituem um desafio principalmente aos professores, pois muitos pertencem ao paradigma anterior no qual as TDIC não fizeram parte de seus processos formativos sociais e acadêmicos, e boa parte dos professores cujas formações acadêmicas ocorreram no bojo da sociedade do conhecimento não tiveram as TDIC como conteúdo curricular de suas formações iniciais. Portanto, a formação continuada inserida na era do conhecimento precisa congregar esses professores à capacitação em uso e inserção de tecnologias na Educação.

O ensino remoto proporcionou uma interação maior dos professores com os pais ou responsáveis dos alunos, já que, estes precisariam atuar juntos para dar continuidade as atividades escolares. Para tal observação pôde-se constatar:

PR or: "Relação com pais foi de apoio, mas teve alguns alunos que não estavam interessados nas aulas, devido também serem em dois turnos."

PR 04: "A relação com os alunos que participam (acessam) melhorou no aspecto de contato, com os pais da mesma forma, pois possibilitou ter contato com alguns pela primeira vez."

Observa-se um forte impacto para educadores, pois teriam que estar cada vez mais presentes no ceio familiar, apresentando disponibilidade para esclarecer as dúvidas dos responsáveis e dos alunos, logo, a jornada de trabalho aumentou. No entanto, alguns pais mostram resistência ao trabalho remoto, muitos estimularam a atenção dos estudantes para outras funções domésticas no horário da aula.

Mais de $40 \%$ das residências não possuem computador e, entre os que possuem, poucos possuem softwares atualizados e capacidade de armazenamento. E são de uso comum de 3 ou mais pessoas (COLEMARX, 2020, p.16).

Muitos pais pelo fato do distanciamento social, ou mesmo por não possuir acesso à internet, ou equipamentos necessários, e não estando presentes em atividades presenciais na escola, a exemplo das reuniões entre pais e professores, a discussão da necessidade de apoio familiar a este momento, provavelmente tem potencializando o afastamento. 
PR o2: "Os pais não contribuíam muito, alegavam que os filhos não tinham acesso à internet $e$ outros atribuíam funções para os filhos no horário da aula. Alguns dos educandos até possuíam internet, mas não participavam porque não tinham compromisso."

PR 07: "O contato com o aluno tem sido muito menor, da mesma forma com os pais dos mesmos e tudo isso gera uma expectativa negativa que é o aumento da evasão escolar."

PR o8: "Quanto aos pais houve afastamento ainda mais e quanto aos alunos, a relação ficou mais superficial já que o ensino virtual propicia isso."

Diante de tantos desafios no contexto educacional no período da pandemia, o uso das tecnologias digitais são um dos mais apontados pelos licenciados, pois grande maioria não possui formação continuada e acabaram se limitando ao ensino convencional. Todavia, os professores do ensino médio buscavam se adaptar intensamente e rápida, em que a escola geralmente contribuía com cursos de capacitação. Para esta inserção, temos:

PR oI: "No início foi difícil se adequar as tecnologias, mas a escola ofereceu cursos de como utilizar as plataformas digitais e fazer as avaliações."

PR 03: "A escola contribuiu com auxílio dos profissionais do TI, com a produção de vídeos e tutorial para orientação do uso das tecnologias. Além de indicar o curso de letramento digital, oferecido pela Secretaria de Educação de Sobral."

PR 04: "Foi um pouco difícil em certos aspectos como ter o equipamento adequado para tal e conhecer as plataformas, contudo não demorou muito para adequar-me. A escola e a Secretaria de Educação forneceram instruções e formação continuada sobre as plataformas e tecnologias."

PR o8: "Inicialmente senti um pouco de dificuldade em me adequar as tecnologias, pois não tinha uma vivência na área da informática, mas com ajuda de colegas professores e até mesmo dos meus alunos consegui me adaptar ao uso das tecnologias como uma das ferramentas essenciais nesta modalidade de ensino, pois diante do que fomos obrigados a nos adaptar, que foi às tecnologias, concluí que jamais um professor será substituído. Mas também ficou muito nítido uma dificuldade, na qual se deu em alcançar todos os alunos já que o acesso à tecnologia ainda não é realidade de todos, o que nos evidenciou a desigualdade social ainda muito existente em nossa realidade. Diante do cenário que nos encontramos tivemos o apoio da escola para melhor realização do processo ensino-aprendizagem."

A falta de preparação dos docentes quanto ao uso das tecnologias digitais, pode gerar déficit na comunicação e aprendizagem dos alunos. Portanto, é necessário que haja incentivo das instituições na formação continuada dos professores. Niz (2017, p.17), acrescenta:

A carência de preparação adequada dos docentes para trabalhar com a TDIC pode gerar uma subutilização ou uso inadequado da tecnologia como recurso de ensino. Para obter resultados positivos e efetivos na utilização da tecnologia no ambiente escolar, é preciso que se reconheça sua potencialidade e se aproprie das contribuições que ela tem a oferecer para a educação. A partir disso, o professor terá clareza sobre sua utilidade, podendo executar uma prática diferenciada. 
Grande parte dos educadores encaram o uso das TIDCs como desafio, já outros veem como uma oportunidade de se reinventar e aprimorar os métodos de ensino, como pode ser observado na fala transcrita abaixo:

PR o2: "Foi inovador, pois além de conhecer novas plataformas de ensino, usei as que já tinha como Instagram e YouTube para fazer resumos e vídeos. A escola forneceu formação continuada, com tutorais e documentos em PDF de como preencher os formulários online $e$ fazer as avaliações.”

Além disso, a educação brasileira que antes seguia um padrão "analógico", devido ao período pandêmico teve que se adequar a era digital. Com isso, o ensino remoto antecipou transformações vistas como impossíveis contribuindo positivamente para avanço da educação e formação dos estudantes do ensino básico, a saber: o uso de tecnologias para aprimorar as aulas presencias.

[...] os professores também já não serão mais os mesmos na vida pós-pandemia. É certo que, ao retornar ao ambiente de sala de aula, todos estarão bem mais preocupados com o que é ser professor. Novas metodologias de ensino e aprendizagem serão mais presentes, tendo o engajamento e a criatividade como estratégias para transformar a prática pedagógica, deixando as aulas mais dinâmicas e aguçando o interesse dos alunos, o que, certamente, favorecerá a aprendizagem. (AGUIAR, 2020, p.59).

Quanto aos pontos positivos do ensino remoto relatados nos discursos dos professores de Biologia, observa-se:

PR or: "Os pontos positivos foram: primeiro uma maneira de não deixar o aluno no ócio e sem apoio. As aulas remotas deixavam o educando ocupados em enriquecer os seus estudos e não ficar presos apenas as notícias ruins."

PR o2:" Acesso do aluno a vários materiais postados no Classroom, maior facilidade na observação das imagens dos slides, prática da escrita no chat, alunos e professores obtiveram um maior domínio das tecnologias digitais. “

PR o3: "Pontos positivos: aprendizagem de conhecimento novo que são as plataformas e as tecnologias; se renovar; comportamento dos alunos; comodidade de estar em casa; participa quem tem interesse, os mesmos da sala de aula, reflexo da realidade."

Notar-se através desses discursos que o ensino remoto no isolamento social, não só foi importante para dar continuidade a formação básica dos educandos, mas também serviu de apoio ao aluno, e uma forma de se distanciar das informações incertas e focar nos estudos. E destaca-se também, o aprendizado e uso das tecnologias digitais como inovação das aulas.

Os ambientes de ensino e aprendizagem ganharam novas formas e espaços, o que antes era transmitido pessoalmente, agora, é apresentado em uma nova configuração. Com eles, surgiram novos desafios e um dos mais urgentes é a recuperação da interação entre professores e estudantes, uma vez que mesmo distantes, se faz necessário a continuação dos processos de ensino e aprendizagem, na tentativa de amenizar os impactos negativos da pandemia para a educação. (SÊNIOR, 2020, p. 13) 
Em contrapartida, de acordo com o relato dos licenciados, o conteúdo de Biologia foi comprometido no que se refere as atividades práticas e didáticas mais facilmente desenvolvidas nas aulas presenciais, a falta de acessibilidade a internet, impossibilitou o professor ter maior contato e conhecimento das dificuldades dos educandos. Outro fator registrado foi o aumento da jornada de trabalho. As redes sociais deixaram de ser uma local de distração, e passaram a ser usado para comunicação entre educadores e educandos, ou seja, em qualquer horário ou dia, o professor poderia ser solicitado, apontam:

PR 04: "Faltou o detalhamento das explicações na lousa através de desenhos e esquemas, foi comprometida a relação professor aluno para perceber simplesmente no olhar do discente se ele compreendeu o conteúdo. Faltou o carisma da turma para com o professor, em diversos momentos foi sentida a necessidade da participação oral. Sentiram-se dificuldades em aplicar os conteúdos e acompanhar os comentários e interrogações dos alunos em tempo real de acordo com o assunto explicado. Faltou a percepção do estado de espírito do aluno e o incentivo particular."

PR o5: "Separar a vida profissional com a pessoal; cansaço do corpo e da mente; alunos enviando mensagens em horários e dias inadequados; dificuldades dos alunos acessarem e participarem."

PR o8: "Abrangência a poucos alunos; desigualdade social, perda de privacidade, sem horário delimitado para trabalhar, acúmulo de mensagens em suas redes sociais."

No tocante a limitação ao acesso à internet e desigualdade social, Colemarx (2020, p. 16), enfatiza:

O uso dos artefatos tecnológicos, por suposto, não pode ser pensado desvinculadamente das condições de habitação dos estudantes da educação básica e superior. Uma ou mais famílias que dividem o mesmo teto, com quatro ou mais pessoas em isolamento, em um espaço inferior a $50 \mathrm{~m}^{2}$, não pode assegurar a concentração mínima para o estudo de seus filhos. E muitos vivem em espaço ainda menor.

Outra preocupação constante, advinda do contexto educacional na pandemia, foi a junção das atividades pessoal e profissional. Os professores dispuseram de pouco tempo, para preparação, no entanto, mesmo diante de tantas adversidades no cenário educacional, esforçaram-se e adaptaram-se para manter o equilíbrio emocional e eficiência na organização profissional. A partir desta perspectiva, observa-se:

PR oI: “Trabalhar em casa misturar o pessoal com profissional exige muita organização não está sendo fácil, principalmente por ser mãe de criança, e a todo momento era solicitada por eles, em vários momentos tive que parar aula para atender as necessidades pessoais. Mas mesmo diante do exposto, consegui avançar bastante no repasse e entrega de conteúdo para turma. Em relação ao aspecto emocional, tive que diversas manter o equilíbrio para conseguir ser eficiente e não deixar que as atividades pessoais interferissem nas aulas."

PR o3: "Um dos fatores prejudiciais no processo da aplicação das aulas foi a falta de interesse dos alunos e assistir às aulas, sendo frustrantes para um professor que tem todo 
um trabalho para preparar aula e não tem um retorno satisfatório dos alunos. Outro fator emocionalmente prejudicial nesse processor foi tempo que ficou muito limitado, deixando ansiedade antes de iniciarem as aulas, até por temer falha das tecnologias e até a perda do acesso à internet."

PR 04: "Houve momentos em que a junção das atividades pessoais e profissionais desestabilizaram meu psicológico, pois já estava com tratamento para a ansiedade $e$ conseguindo manter-me bem, porém com advindo do ensino remoto em que houve essa junção de pessoal com profissional veio crises de ansiedade novamente, prejudicando na minha eficiência."

PR 05: "Considero que minha eficiência profissional não foi comprometida, pois, independente da situação sempre me esforcei e dei o meu melhor para ser uma boa profissional e a pandemia não me tirou isso. Temos que ser profissionais e darmos o nosso melhor independente do momento ou situação. Claro que por vezes sinto o emocional um pouco fragilizado pela circunstância nunca vivida, mas aí lembro da oportunidade de trabalhar em casa que Deus me deu e recupero as energias para dar continuidade aos trabalhos com alegria, otimismo e gratidão."

PR o6: "Por não terem acesso à tecnologia ou pela falta de interesse não vemos o retorno esperado na frequência nas aulas e das atividades enviadas. Causando assim transtorno $e$ frustração por parte dos professores, que se dedicam muito além de sua carga horária e não veem o resultado esperado."

PR 07: "Eu mesmo passei um bom tempo até digerir com a ideia do ensino remoto, hoje já me sinto bem mais confiante e isso me motiva para que eu possa melhorar minha prática a cada dia. Não está sendo fácil, no início me senti muito deprimido, impotente, mas já me sinto melhor e mais preparado."

PR o8: “A parte emocional me abalou, pois sempre procurei otimizar o tempo com o que a nova sistemática oferece."

Certifica-se nas falas do corpo docente que possuíram dificuldades em separar a vida pessoal e profissional, alguns não tinham um ambiente adequado designado ao trabalho, e por ter filhos, eram interrompidos no momento da aula. Entretanto, mesmo diante do exposto, mostraram eficiência ao concluir o que era proposto na ementa escolar. $O$ aspecto emocional, também foi apontado pela maioria como o principal ponto de interferência na realização das obrigações docente. O deficit de participação e retorno satisfatório dos discentes, causou ansiedade, impotência, frustração e transtornos aos educadores.

O profissional de educação, pode ser acometido por outra problemática, talvez desconhecida, que seja, a frustração do não conhecimento e domínio pleno da ferramenta, ampliando sua carga horária de trabalho em busca dessa competência. Cabendo, ainda, mais atenção, pois tudo isso, passando pelo processo pandêmico, de total isolamento social, requer de equilíbrio emocional e boas práticas para manter, também, uma saúde física, mental e financeira (BARBOSA; VIEGAS; BATISTA,2020, p.277).

Por outro lado, outra parte de licenciados não apresentaram dificuldades no trabalho domiciliar, e pelo fato de serem jovens, tinham domínio das tecnologias e inovação de suas aulas. 
Dessa forma, demostrando controle no aspecto emocional e eficiência profissional, como é explícito no relato abaixo:

PR o2: " Não houve dificuldade em trabalhar em casa, pois já busco inovar em minhas aulas e gosto muito de tecnologias, e ainda possuía um espaço no qual ninguém interferia. Fui muito eficiente, entregava todas as planilhas das atividades no prazo. Mas diminui a concentração de conteúdo, para atender as necessidades daquele momento."

O isolamento social deixou claro, o quanto os educadores são essenciais para a sociedade, na perpetuação da informação coerente e conceituada. Em seu discurso, Oliveira (2020, p.4I) complementa:

E destaco, ainda, que tivemos um ganho com essa situação: a sociedade nos enxergou, reconheceu a importância do nosso trabalho, que ser professor é uma profissão. Não, é qualquer coisa que qualquer um faz a qualquer hora e em qualquer situação. Sairemos mais respeitados pelos pais, pelas famílias, pelas comunidades, por perceberem a importância do professor e a falta que fazemos na educação de seus filhos.

Diante disso, percebe-se a relevância nos discursos dos professores de Biologia, quanto a percepção destes como profissionais da educação a partir das experiências e transformações vivenciadas durante o período de isolamento social provocado pela pandemia da Covid-19, tem-se:

PR or:" A Biologia é a parte da ciência que ensina os alunos o que é o vírus, suas causas, tratamentos e prejuízos para o organismo. Estudar Biologia é ter mais informações da forma de contágio e as prevenções contra a Covid-19. Portanto, a educação é essencial nesse momento de pandemia. A maioria das pessoas que não cumprem o isolamento social, não possuem essa instrução, ou seja, os educadores influenciam na perpetuação do conhecimento orientando os jovens a como se comportarem diante do isolamento social.

PR 03: "É possível perceber-se como profissional que dispõe de novos horizontes para a educação, reconhecendo novas tecnologias para ter acesso ao aluno. Mas também reconhecendo a importância do professor nas aulas presenciais como ser indispensável no processo de ensino, aprendizagem e relação professor aluno, sendo esses dois aspectos integrados para favorecer aprendizagem do aluno."

PR 04: "Essa experiência durante o período de isolamento social provocado pela pandemia COVID-I9 veio confirmar a percepção de que é preciso repensar o nosso sistema educacional, deixar de ser tão conteudista e da técnica para buscar uma educação do ser humano, humanitária, visando os valores e sua aplicação no cotidiano."

PR 05: "Percebo que adaptação e aprendizagem é algo contínuo, que o novo assusta, mas que traz muito preparo e aperfeiçoamento para sermos cada dia mais profissionais capazes $e$ melhores para tentar mostrar que a educação ainda é a melhor saída. "

PR o6: "Sinto-me capaz para suprir as necessidades do ensino online e, ao mesmo tempo impotente por despender tanto tempo e trabalho e não conseguir chegar até a grande maioria dos alunos, para não conseguir o retorno desejado."

PR o7: "No início senti muito medo, insegurança, impotência, mas cheguei à conclusão de que enquanto professor, tenho um papel importantíssimo que é auxiliar meus alunos a passar por essa situação da melhor forma possível. É isso que está me dando forças e 
ajudando a superar meus medos e angústias. Muitos jovens, nesse momento, estão necessitando do "meu melhor" e estou disposto a não os decepcionar."

PR o8: “ Como em qualquer época o profissional deve sempre se reciclar para se adequar ao momento independente de fenômenos que alterem o perfil típico da educação, pois o profissional necessita está sempre atualizado com todas as informações, pois mesmo que não seja de sua área. O ensino remoto impõe várias limitações e desafios. Desafios que fogem de nosso poder de resolução, tais como, poder aquisitivo da família, pais e mães que não impõem regras aos filhos, o acesso à tecnologia, professores aprendendo na prática usar as ferramentas tecnológicas. Logo, o profissional deve estar atento ao recepcionar novos desafios para ao invés de se frustrar abraçar a causa como algo que ajude na sua formação. $E$ isso que devemos fazer, pegar todos os desafios deste ensino remoto, pandemia e isolamento social para aumentar nossos conhecimentos na abrangência e abordagens na vida da gente enquanto professor e de nossos alunos."

Verifica-se nos relatos dos docentes o conhecimento biológico está sendo importante no enfrentamento da pandemia, ou seja, o professor de Biologia teve um papel ainda maior nesse período, no repasse das informações coerentes para os alunos. A relação do professor-aluno é indispensável no avanço de um aprendizado significativo, sendo evidente que o sistema educacional brasileiro precisa ser reconstruído, deixar de ser conteudista. O educador precisa sair da zona de conforto, e ir em busca de capacitação profissional, manter-se atualizado nas TIDCs e inovações nas futuras aulas presenciais.

\section{Considerações finais}

Dada à relevância do assunto, tornar público o quanto o corpo docente foi essencial no período da pandemia do vírus (SARS-COV-2), na instrução dos estudantes diante de um novo paradigma educacional. Avaliar os discursos dos professores de Biologia do nível médio, quanto a criatividade, eficiência, significados e aspectos emocionais, contribuirá na divulgação da importância dessa classe de trabalhadores durante a pandemia, enfatizando que o professor precisa ser cada vez mais reconhecido, pois, mesmo não estando preparado profissionalmente e psicologicamente, estão sempre em busca se reinventar e instruir os alunos.

Apesar dos discentes mostrarem dificuldades quanto a adaptação do ensino remoto, os docentes abdicaram da privacidade, mesmo com uma transformação inesperada na forma de lecionar sem tempo suficiente para preparação emocional e profissional, mostraram eficiência e usaram a criatividade e, acima de tudo, comprometimento com os alunos. Portanto, relatar as experiências desses profissionais ajudará na valorização do trabalho desempenhando pelos professores, por parte dos alunos e comunidade escolar, e servirá de exemplo ou apoio para os licenciandos que não tiveram vivência com ensino na pandemia. E ainda, como o trabalho foi realizado em municípios da região 
Norte do Ceará, os resultados contribuirão no conhecimento sobre a situação atual do sistema educacional do Nordeste, que geralmente não são enfatizados no país.

Com o isolamento social, ficou ainda mais claro, que o professor é indispensável na instrução e formação dos alunos, e o contato entre ambos é crucial no processo de ensino e de aprendizagem. A formação inicial dos docentes, deixa lacunas quanto ao uso de tecnologias, por isso a formação continuada deve estar presente no ideário formativo do profissional da educação. O licenciado em Biologia, do nível médio, precisa estar atualizado sobre as informações conteudistas, mas usar a criatividade no processo didático de transposição significada desses conhecimentos, a fim de que possam despertar o interesse dos alunos.

Outro ponto importante para esse processo é o reconhecimento das dificuldades estruturais como o acesso à internet de qualidade e/ou equipamentos disponíveis, por exemplo, tornando o planejamento estratégico do professor, uma ferramenta de suma importância para o atendimento à diversidade e dinâmicas sociais dos alunos.

No que se refere a eficiência, os discursos evidenciam a junção das atividades domiciliares e escolares, há uma quebra de privacidade, os professores dispõem dos espaços compartilhados de suas casas, muitas vezes inadequados para o desenvolvimento das aulas.

Os professores apontam que suas redes sociais são solicitadas desordenadamente e a qualquer horário, aumentando a jornada de trabalho do educador. No entanto, o acúmulo de atividades, uso de tecnologias e ausência do contato presencial com os alunos, interferiu psicologicamente em muitos casos, destacando em alguns momentos desânimo, ansiedade, frustração, impotência e preocupações exageradas.

Diante do exposto, grandes transformações resultam em evolução e aprendizados significativos, apesar das adversidades advindas do ensino remoto, os professores sairão mais fortalecidos emocionalmente por insistir, e profissionalmente alcançando bons resultados usando as TDICs, propostas pela escola. E todas essas vivências contribuirão no aprimoramento das sequências didáticas, sejam em modalidades de aulas presencias, híbridas ou virtuais, e no avanço da reconstrução do sistema educacional brasileiro.

\section{Referências bibliográficas}

AGUIAR, Felipe. Pandemia da covid-ı9 e demandas de atuação docente. Revista Diálogos Acadêmicos, Fortaleza, v. 9, n. I, p.59, 2020. Disponível em $<$ Ihttp://revista.fametro.com.br/index.php/RDA/article/view/268 > Acesso em: II dez.2020 
ANED. Dados sobre educação domiciliar no Brasil. Associação Nacional de Educação Domiciliar, 2010. Disponível em: https://www.aned.org.br/sobre-nos/quem-somos-aned. Acesso em: in de novem. 2020.

BARBOSA, André.; VIEGAS, Marco.; BATISTA, Regina. Aulas presenciais em tempos de pandemia: relatos de experiências de professores do nível superior sobre as aulas remotas. Rev. Augustus, v.25, n. 51. p. 277, Rio de Janeiro, 2020. Disponível em: < https://apl.unisuam.edu.br/index.php/revistaaugustus/article/view/565> Acesso em: 15 dez. 2020.

BENEDITO, Samiles. C.; FILHO, Pedro. A educação básica cearense em época de pandemia de coronavírus(covid-19): perspectivas e desafios no cenário educacional brasileiro. Revista Nova Paideia -Revista Interdisciplinar em Educação e Pesquisa. Brasília/DF, v. 2, n. 3.p. 58 - 71 - 2020. Disponível em:<http://novapaideia.org/ojs/ojs-2.4.8 3/index.php/RIEP/article/view/58>Acesso em: 20 de novem. 2020 .

BORN, Bárbara. Transformar a formação de professores pela prática: um desafio possível: o papel da prática na formação inicial de professores. Instituto Península, Profissão Docente. - I. ed. - São Paulo: Moderna, p. 25, 2019.

BRASIL. lei no 240I/ı9, de I3 de julho de 1990. Projeto cria regras para educação domiciliar no Brasil. Câmara dos Deputados, Brasília - DF,2020. Disponível em< amara.leg.br/noticias/556888-projetocria-regras-para-educacao-domiciliar-no-brasil/>Acesso em: is de novem. 2020.

BRASIL. Constituição 1988. Constituição da República Federativa do Brasil: promulgada em 5 de outubro de 1988. Disponível em: www.mec.gov.br/legis/default.shtm. Acesso em: 24 de novem. 2020.

COLEMARX. Em defesa da educação pública comprometida coma igualdade social: por que os trabalhadores não devem aceitar aulas remotas. Rio de Janeiro, 2020. Disponível em: http://www.colemarx.com.br/wp-content/uploads/2020/o4/Colemarx-texto-cr\%C3\%ADticoEaD-2.pdf. Acesso em: 22 de novem. 2020.

GOMES, Lincoln. As tecnologias digitais e a prática docente no ensino médio de Biologia: um estudo de caso. 2018. roof. Dissertação (Mestrado Profissional) - Programa de Pós-Graduação do Centro de Ciências da Universidade Federal do Ceará,2or8. Disponível em: 〈http://www.repositorio.ufc.br/handle/riufc/3459I> Acesso em: 26 de novem.2020.

LOUZANO, Paula et al. O curso de pedagogia da Universidade Diego Portales, Chile. O papel da prática na formação inicial de professores. Instituto Península, Profissão Docente. - I. ed. - São Paulo: Moderna, p. 153, 2019.

MALHOTRA, Naresh. Pesquisa de marketing. 3.ed. Porto Alegre: Bookman, 200 .

FERREIRA, Maria, L.; NETA, Maria. Percepção dos professores no uso da educação a distância na formação continuada. In: XI Encontro Cearense de História da Educação e Memória da Educação História da Educação: real e virtual em debate. Fortaleza-CE. p. 963-965, 2012.Disponível em< repositorio.ufc.br/bitstream/riufc/24762/1/2012_eve_dmbpaes.pdf> Acesso em: 05 novem. 2020.

NIZ, Claudia. A Formação Continuada do professor e o uso das tecnologias em sala de aula: tensões, reflexões e novas perspectivas. Dissertação (Mestrado em Educação Escolar) - Universidade 
Estadual Paulista, Faculdade de Ciências e Letras, São Paulo, 2017. Disponível em:<wwws.fclar.unesp.br > Acesso em: io dez. de 2020.

OLIVEIRA, Maxwell. Metodologia científica: um manual para a realização de pesquisas em administração. Manual (pós-graduação) - Universidade Federal de Goiás, p.24, 2011.

OLIVERA, Sérgio. Pedagogas e professoras em tempos de pandemia. Pedagogia em Ação, Belo Horizonte, $\quad$ v.13, n. $\quad$ I, O20. $\quad$ Disponível http://periodicos.pucminas.br/index.php/pedagogiacao/issue/view/74I> Acesso em: o4 de set. 2020.

PASCHOALINO, Jussara.; Ramalho, Maria, L.; QUEIROZ, Vírginia. Trabalho docente: o desafio de reinventar a avaliação em tempos de pandemia. Revista Labor, Fortaleza-CE, V I, N. 23, 2020. Disponível em: 〈http://www.periodicos.ufc.br/labor/index> Acesso em: 07 de out. 2020.

SEGATTO, Catarina.; LOUZANO, Paula. Em busca de consensos e mudanças incrementais: o papel da prática na formação inicial de professores. Instituto Península, Profissão Docente. - I. ed. São Paulo: Moderna, p.181-184, 2019.

SÊNIOR, Maria, F. Afetividade: interação entre professores e estudantes nos novos ambientes de aprendizagem em tempos de pandemia. Universidade Federal da Paraíba, João Pessoa, p.13, 2020. Disponível em:<https://repositorio.ufpb.br/jspui/handle/123456789/19207 > Acesso em: 13 dez. 2020

SILVA, Denis. A formação continuada em tecnologias digitais ofertada no paraná sob a ótica de professores da rede estadual de foz do Iguaçu. Dissertação(mestrado), Universidade Estadual do Oeste do Paraná, Campus de Foz Iguaçu, Programa de Pós- Graduação em Ensino, Paraná, 2018. Disponível em:<http://tede.unioeste.br/handle/tede/3647> Acesso em: 03 de dez. 202I.

SILVA, Monique. Homeschooling: a educação domiciliar em tempos de pandemia. Redação: Desafios da educação, 2020. Disponível em: 〈https://desafiosdaeducacao.grupoa.com.br/educacaodomiciliar-pandemia/ >Acesso em: ro de novem.2020. 